\title{
Mechanical and Parametric Analysis of Cracks in Polypropylene Fiber Concrete U-Shaped Girder
}

\author{
Xu Dong, ${ }^{1}$ Shuchen Li, ${ }^{1}$ Zhenquan Deng, ${ }^{1}$ Jian Guo, ${ }^{2}$ and Haican Zhou ${ }^{2}$ \\ ${ }^{1}$ Geotechnical and Structural Engineering Rexsearch Center, Shandong University, Jinan 250061, China \\ ${ }^{2}$ The Fifth Project Co., Ltd. of China Railway Bureau 14 Group, Taian 271021, China \\ Correspondence should be addressed to Shuchen Li; geoscli@163.com
}

Received 16 June 2017; Revised 4 October 2017; Accepted 17 October 2017; Published 6 November 2017

Academic Editor: Marino Lavorgna

Copyright (c) $2017 \mathrm{Xu}$ Dong et al. This is an open access article distributed under the Creative Commons Attribution License, which permits unrestricted use, distribution, and reproduction in any medium, provided the original work is properly cited.

\begin{abstract}
The U-shaped girder is a type of open thin-walled structure, which is used in urban rail transit engineering. Although it employs polypropylene fiber concrete to avoid cracks, the girder is still easier to crack than other traditional structures owing to its special open thin-walled cross section. In this study, a cracking accident of a U-shaped girder, which happened during the prestressed steel tensioning, was studied by field investigation and mechanical analysis through the finite element (FE) method. An outline of the cracks was presented. The nonlinear material properties of the polypropylene fiber concrete and steel were discussed and used in the finite element model. The effects of the main design parameters, such as the flange slab thickness, anchorage position, and prestressed steel layout, were evaluated based on the results of the FE analysis. The results indicate that the extremely low rigidity of the web and oversize of the web longitudinal prestressed steels are the main reasons for the cracks. The risk of cracks can be reduced by increasing the thickness of the flange slab and changing the anchorage position and prestressed steel layout. Some suggestions are provided for avoiding cracks based on the results of the research.
\end{abstract}

\section{Introduction}

In recent years, with the development of China's economy, traffic congestion and oversaturation are some of the major factors restricting the urbanization process in the country. Rail transit, as a low-contamination, low-energy consumption, and high-efficiency means of transportation, has played a vital role in the urban transportation system. Therefore, many cities have adopted urban rail transit development as an important strategy to solve traffic problems.

The U-shaped girder is a new type of viaduct structure for urban rail transit systems in China, and it is based on the channel girder. Compared to many traditional bridge types, such as the box girder, T-shaped, and hollow slab girder, the U-shaped girder has many advantages. It has an open thinwalled U-shaped section, which is composed of a bottom slab, web, and flange slab. As shown in Figures 1 and 2(a), the structure uses the bottom slab to support the rail tracks and trains, and thus it can reduce the height of the girder and the rail station, while, simultaneously, the webs of the Ushaped girder can help isolate train noises and make trains run more safely [1]. In addition, the U-shaped girder uses prestressed steel and polypropylene fiber (Figure 2(b)), which can obviously increase its load bearing capacity and crack resistance [2]. Furthermore, precast construction is applied for U-shaped girder construction to achieve construction safety, shorten the construction time, and reduce costs. Most importantly, the U-shaped girder is lighter and more artistic than other types of traditional bridge girders.

During prestressed concrete girder construction, the stress of the girder will suddenly change owing to posttensioning. If the induced tensile stresses are higher than the tensile capacity of the concrete, there is a risk that the girder could either crack or collapse, and several similar accidents have happened in China and other countries in recent years [3-5]. Simultaneously, cracks are often a major problem influencing the structure construction quality and load-carrying capacity. To avoid these problems, numerous studies are being performed on construction cracks [3-8].

Unlike traditional bridge girder types, the U-shaped girder is an open thin-walled structure. The rigidity of the 


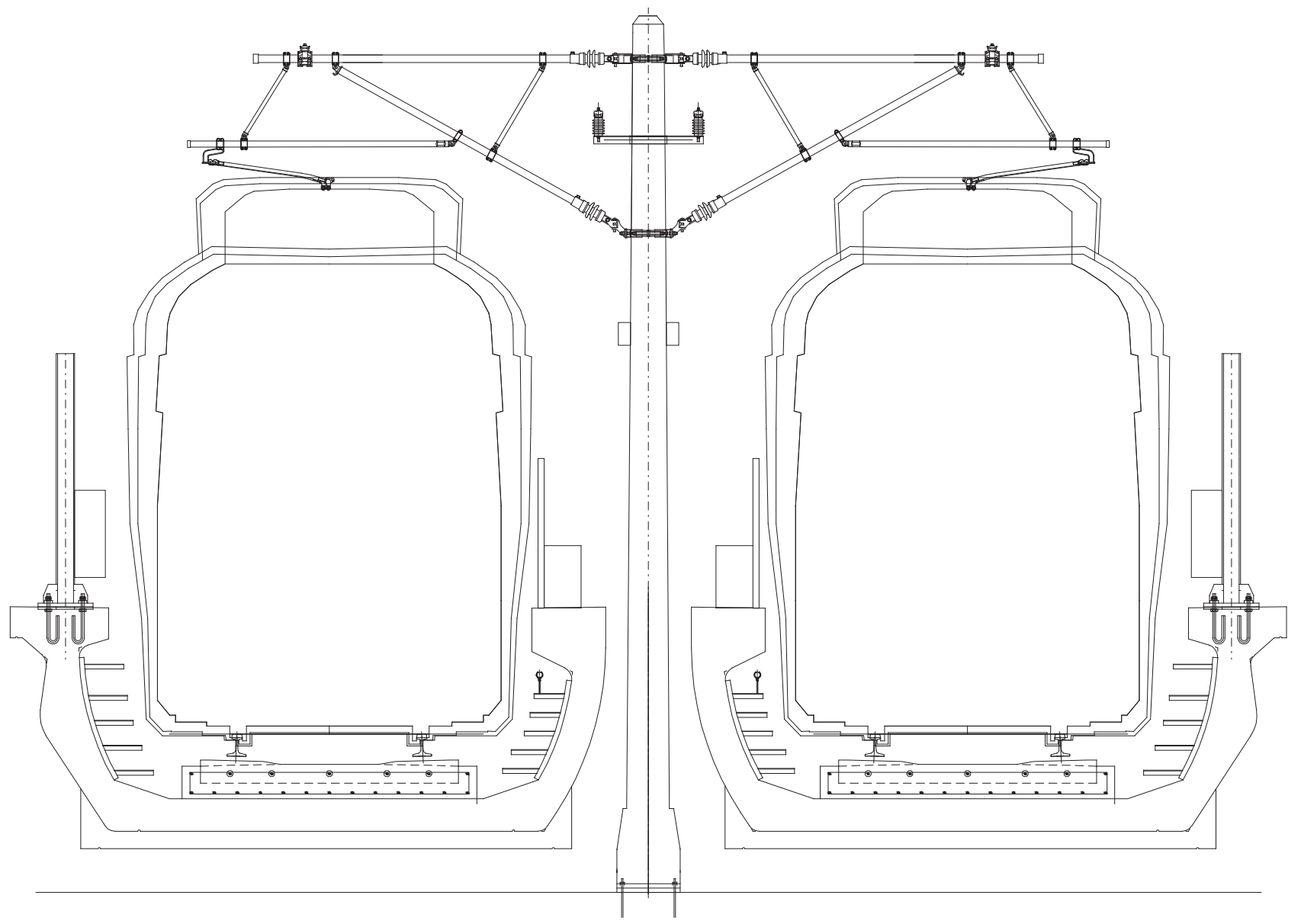

FIGURE 1: Structure diagram of U-shaped girder for urban rail transit.

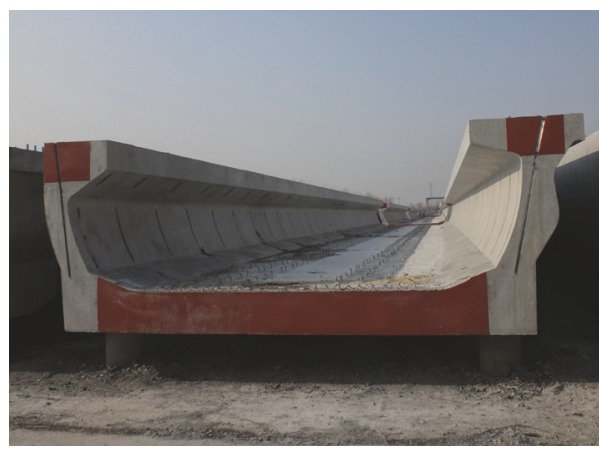

(a) U-shaped girder

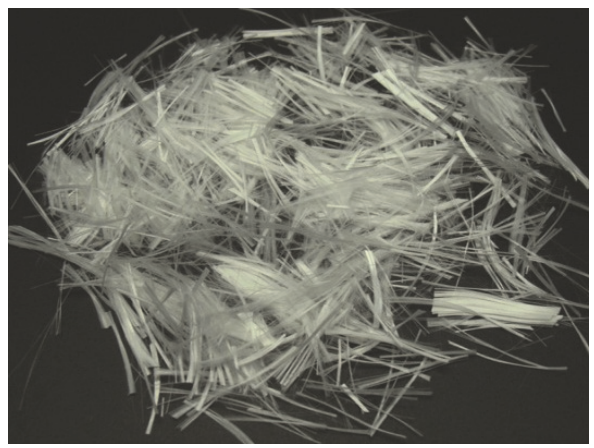

(b) Polypropylene fiber

FIGURE 2: Photographs of U-shaped girder and polypropylene fiber.

girder, especially its web rigidity, is lower than that in other traditional structures $[2,9-12]$. Thus, the structure design parameters are more sensitive to cracks, in particular, during posttensioning construction.

In this paper, a cracking accident of a U-shaped girder, which happened during the tensioning construction phase, will be shown in detail. The finite element software package
ABAQUS is used to analyze the causes of cracks [13]. The nonlinear material properties of polypropylene fiber concrete and steel are discussed and used in the FE model. The effects of the design parameters, such as the flange slab thickness, anchorage position, and prestressed steel layout, are evaluated as countermeasures. Based on the results of the research, some suggestions are provided for avoiding cracks. 


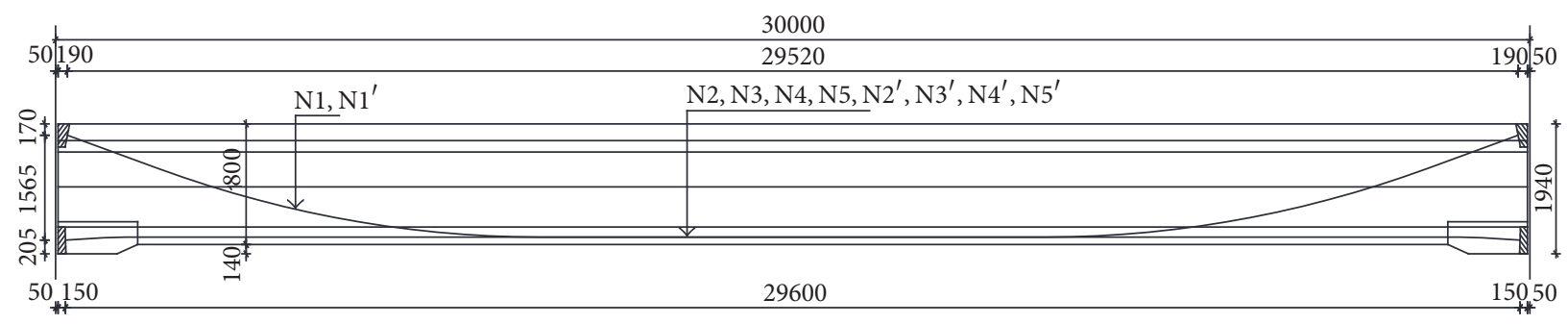

FIGURE 3: Elevation drawing and layout of the longitudinal prestressed steels in U-shaped girder (unit: $\mathrm{mm}$ ).

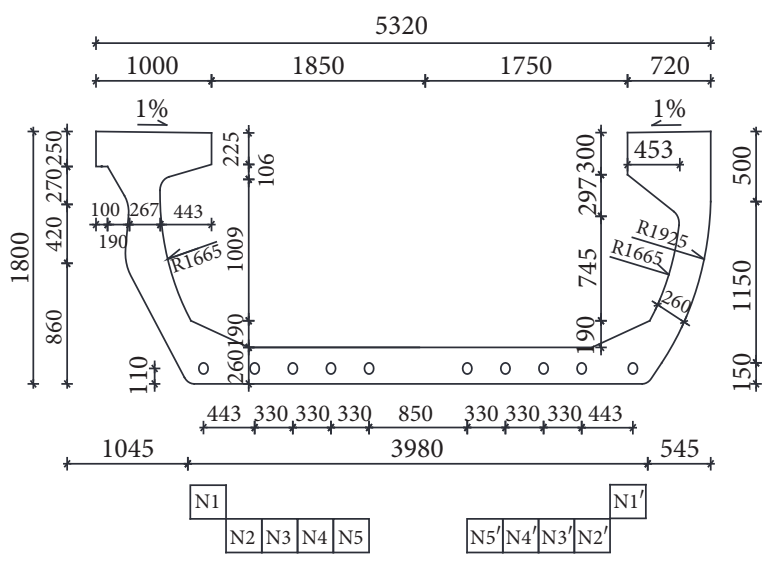

(a) Cross section at mid-span

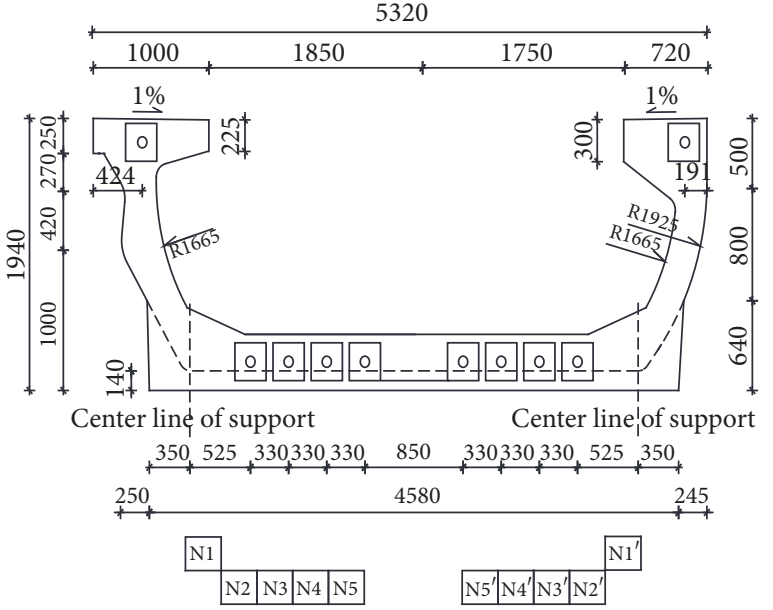

(b) Cross section at the support

FIGURE 4: Cross section of U-shaped girder (unit: $\mathrm{mm}$ ).

\section{Details of the Girder and Cracks Patterns}

2.1. Girder. The U-shaped girder on which the cracks were found is a prestressed simply supported concrete structure used in a rail transit project of China, with a span length of $30 \mathrm{~m}$, as shown in Figure 3. In the mid-span of the girder, the height is $1.8 \mathrm{~m}$, the top width is $5.32 \mathrm{~m}$, the bottom width is $3.98 \mathrm{~m}$, and the thickness of the web and bottom slabs is $0.26 \mathrm{~m}$, as shown in Figure 4(a). Polypropylene fiber concrete with a $0.9 \mathrm{~kg} / \mathrm{m}^{3}$ fiber dosage and C55 standard strength grade steel are used in the girder. Longitudinal prestressed steels, which are designed combining longitudinal and vertical bending as required, are set up in the girders. The longitudinal prestressed steels use 270 grade steel strands with a standard strength of $R_{y}^{b}=1860 \mathrm{MPa}$ and control tension stress $\sigma_{k}=0.75 R_{y}^{b}=1395 \mathrm{MPa}$. As shown in Figure 4(b), the longitudinal prestressed steels $\mathrm{N} 1$ and $\mathrm{N1}^{\prime}$ are located in the web, the longitudinal prestressed steels N2 to $\mathrm{N} 5$ and $\mathrm{N} 2^{\prime}$ to $\mathrm{N}^{\prime}$ are located in the bottom slab, and all the prestressed steels are stressed and anchored at the end of the girder, after the girder is cast. The design parameters of prestressed steels are listed in Table 1 . The girders are constructed offsite. They are then trucked or barged to the bridge site and lifted into place with a bridge erecting machine span-by-span.
2.2. Polypropylene Fiber Concrete. Concrete has proved to be a construction material with good compressive but low tensile strengths, and the tensile strength is typically around onetenth of the compressive strength. To improve the mechanical properties of plain concrete, fiber-reinforced concrete has been introduced and is widely used in special structures with high performance requirements. The most common fibers mixed with a concrete matrix are steel, glass, or polypropylene. Many studies state that the toughness indexes of fiber concrete seem to increase by 3-35\% compared with plain concrete [14-16].

Polypropylene fiber, which offers better construction workability and lower cost than steel and glass, has been widely used in fiber concrete in recent years. In polypropylene fiber concrete, the volumetric fraction of the fiber plays an important role in concrete performance. Sadiqul Islam and Gupta [17] conducted material performance tests and evaluated the strength, plastic shrinkage, and permeability of polypropylene fiber concrete in various proportions (namely, $0.10 \%, 0.15 \%, 0.20 \%, 0.25 \%$, and $0.30 \%$ ) by volume of concrete. It was concluded that $0.1 \%$ polypropylene fiber was the optimal proportion for concrete, considering the compressive ( $2 \%$ reduction) and tensile ( $39 \%$ increase) strengths and shrinkage (50\% crack reduction) properties of concrete [17].

Therefore, for U-shaped girders, which is a special open thin-walled structure, polypropylene fiber concrete with 
TABLE 1: Design parameters of prestressed steels.

\begin{tabular}{lcccc}
\hline Object & Specification & Quantity of steels & Location & $\begin{array}{c}\text { Control tension stress } \\
(\mathrm{MPa})\end{array}$ \\
\hline $\mathrm{N} 1, \mathrm{N1}^{\prime}$ & Фs 15.2 & 7 & Web & 1246.2 \\
$\mathrm{~N} 2, \mathrm{~N}^{\prime}$ & Фs 15.2 & 11 & Bottom slab & 1339.2 \\
$\mathrm{~N} 3, \mathrm{~N} 3^{\prime}$ & Фs 15.2 & 10 & Bottom slab & 1339.2 \\
$\mathrm{~N} 4, \mathrm{~N} 4^{\prime}$ & Фs 15.2 & 10 & Bottom slab & 1339.2 \\
$\mathrm{~N} 5, \mathrm{~N}^{\prime}$ & Фs 15.2 & 10 & Bottom slab & 1339.2 \\
\hline
\end{tabular}

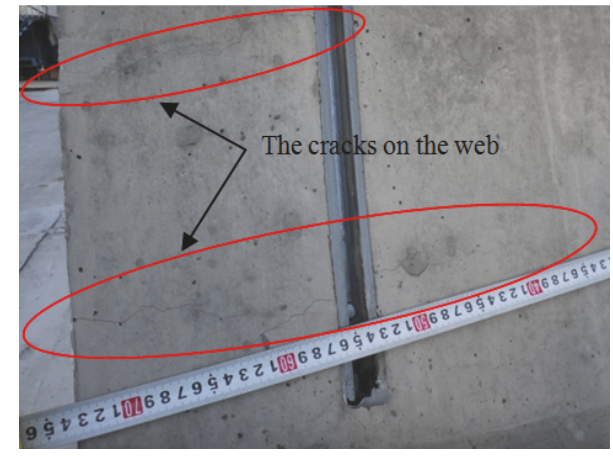

(a) Typical cracks on the webs

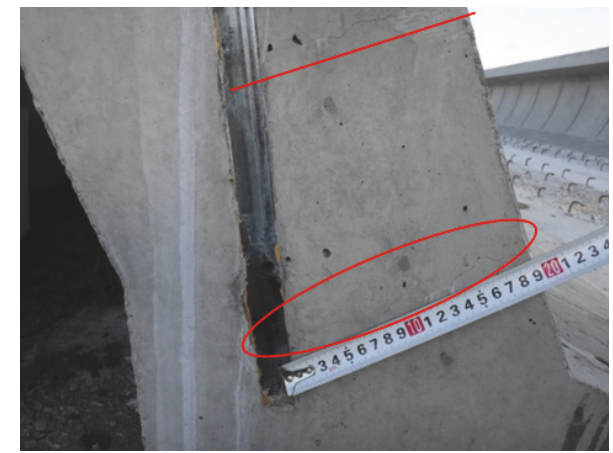

(b) Typical cracks on the beam-end

FIGURE 5: The cracks at the joint areas of the web and beam-end.

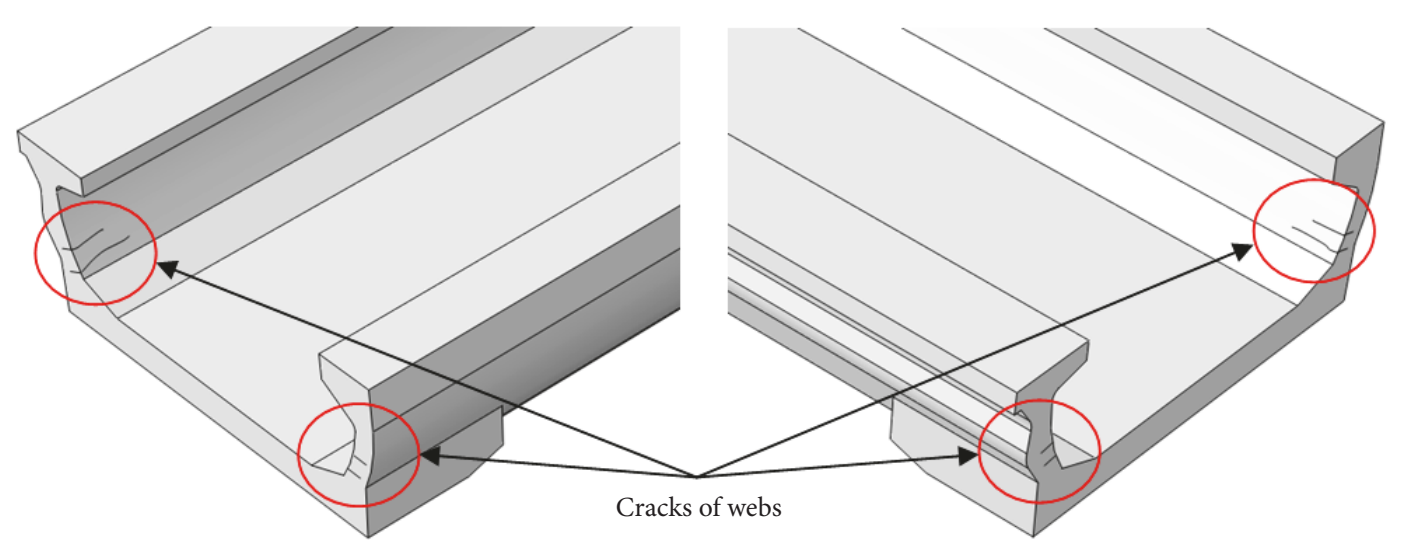

FIGURE 6: Crack details and overall crack patterns of bridge.

$0.10 \%$ of fiber $\left(0.9 \mathrm{~kg} / \mathrm{m}^{3}\right)$ was used to prevent shrinkage cracks and improve the tensile strength of concrete.

2.3. Cracks. After the tensioning process of prestressed steels $\mathrm{N} 1$ and $\mathrm{N1}^{\prime}$ was finished, a few longitudinal cracks were found near both the end regions of the U-shaped girder webs, as shown in Figure 5. The inspection revealed that all cracks were generated and developed from the end of the girder. The crack length was approximately $70 \mathrm{~cm}$, approximately parallel to the centerline of the girder, and near the middle of the webs, as shown in Figure 6. The crack width was approximately $0.4 \mathrm{~mm}$. Additional extensions or further crack development did not occur.
The cracks affect the appearance of the girder, its usage lifespan, and even the safety of the structure. Therefore, it is very important to confirm the cause of cracks and the appropriate countermeasures for crack prevention in $\mathrm{U}$ shaped girders.

\section{Finite Element Models and Mechanical Analysis}

It is assumed that these cracks were not caused by manufacturing errors, such as dry shrinkage and insufficient concrete cover, because the U-shaped girder was cast, cured, and tensioned following precise quality control measures. 


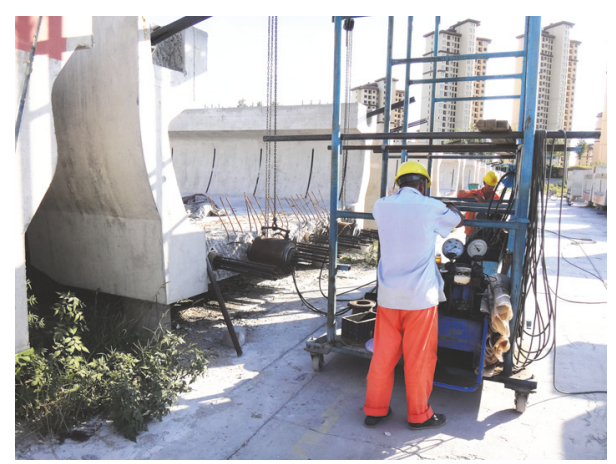

FIGURE 7: Posttensioning construction of U-shaped girder.

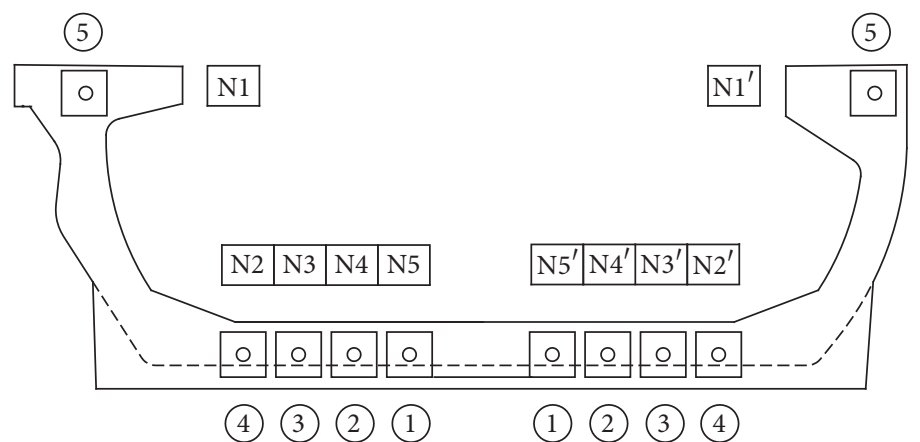

Figure 8: Prestressing sequence of U-shaped girder.

Therefore, the FE model of the U-shaped girder was set up describing its structural behavior during construction.

3.1. Construction Sequence and Method. As shown in Figure 7 , the prestressed steels of the U-shaped girder were symmetrically tensioned by a hydraulic jack. Figure 8 depicts the position of the anchorages and the prestressing sequence for posttensioning. The tension procedure for the U-shaped girder was as follows. (1) When the concrete reached $80 \%$ of its standard strength, the prestressed steels $\mathrm{N} 1$ and $\mathrm{N}^{\prime}$ were symmetrically tensioned to $600 \mathrm{MPa}$, and after that the prestressed steels from $\mathrm{N} 5$ and $\mathrm{N} 5{ }^{\prime}$ to $\mathrm{N} 2$ and $\mathrm{N} 2{ }^{\prime}$ were symmetrically tensioned to $700 \mathrm{MPa}$ for lifting the girder. (2) When the concrete reached $80 \%$ of its standard strength, the prestressed steels $\mathrm{N} 1$ and $\mathrm{N1}^{\prime}$ were symmetrically tensioned to $1246.2 \mathrm{MPa}$, and after that the prestressed steels, from N5 and $\mathrm{N} 5^{\prime}$ to $\mathrm{N} 2$ and $\mathrm{N} 2^{\prime}$, were symmetrically tensioned to 1339.2 MPa for reaching the final design requirements. Thus, as it can be seen, whether by initial or final tensioning, the prestressing sequence contains five steps, that is, (1) $\rightarrow$ (2) $\rightarrow$ (3) $\rightarrow$ (4) $\rightarrow$ (5).

\subsection{Mechanical Analysis for Crack Assessment}

3.2.1. Introduction to FE Model. The commercial structural finite element analysis program ABAQUS was used to estimate the risk of cracking in detail. As shown in Figure 9, in the nonlinear FE model, C3D8R elements are used for the polypropylene fiber concrete, and T3D2 elements are used for all the steels. The U-shaped girder is supported on the tensioning bed, and hinge joint conditions are assumed. In the FE model, the structural design dimension parameters are considered according to the original design, and the construction sequence is also simulated.

3.2.2. Stress-Strain Relationship of Polypropylene Fiber Concrete and Steels. In recent years, many researchers have carried out related studies on the stress-strain relationship of polypropylene fiber concrete. Liang et al. $[18,19]$ conducted a series of material experiments and theoretical analyses on polypropylene fiber concrete. According to the results of tensile and compressive tests, the damage constitutive model of the tensile and compression characteristics was established, and, simultaneously, the curve shape parameters of the polypropylene fiber concrete damage factor were determined.

Based on this research achievement [18], the relationship between the polypropylene fiber concrete stress $\sigma_{c}$ and strain $\varepsilon_{c}$ is presented in Figure 10, where (1) is the relationship under uniaxial compression and (2) is the relationship under uniaxial tension. $E_{c}$ is Young's modulus of polypropylene fiber concrete, $d_{\mathbf{c}}$ and $d_{\mathbf{t}}$ are the damage evolution parameters under uniaxial compression and tension, which can be calculated using the formulas from the code for design of concrete structures [20] and measured values of polypropylene fiber concrete experiments [18].

$$
\begin{aligned}
& \sigma_{c}=\left(1-d_{\mathrm{c}}\right) E_{\mathrm{c}} \varepsilon_{c}, \\
& \sigma_{c}=\left(1-d_{\mathrm{t}}\right) E_{\mathrm{c}} \varepsilon_{c} .
\end{aligned}
$$




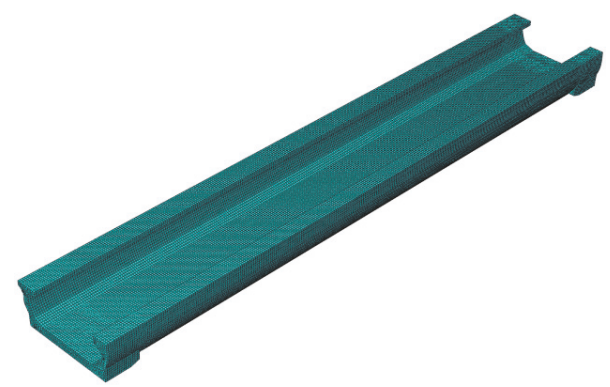

(a) FE model of the whole girder

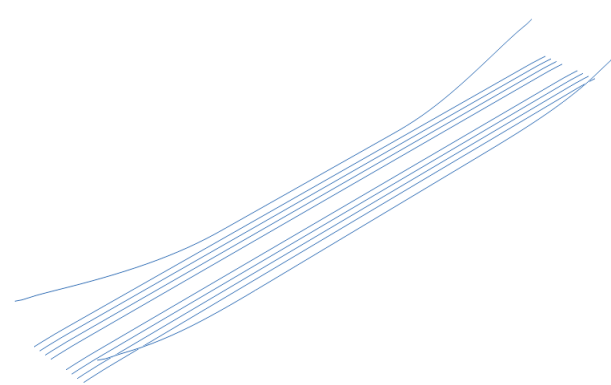

(b) FE model of the prestressed steels

FIGURE 9: Finite element model for the U-shaped girder.

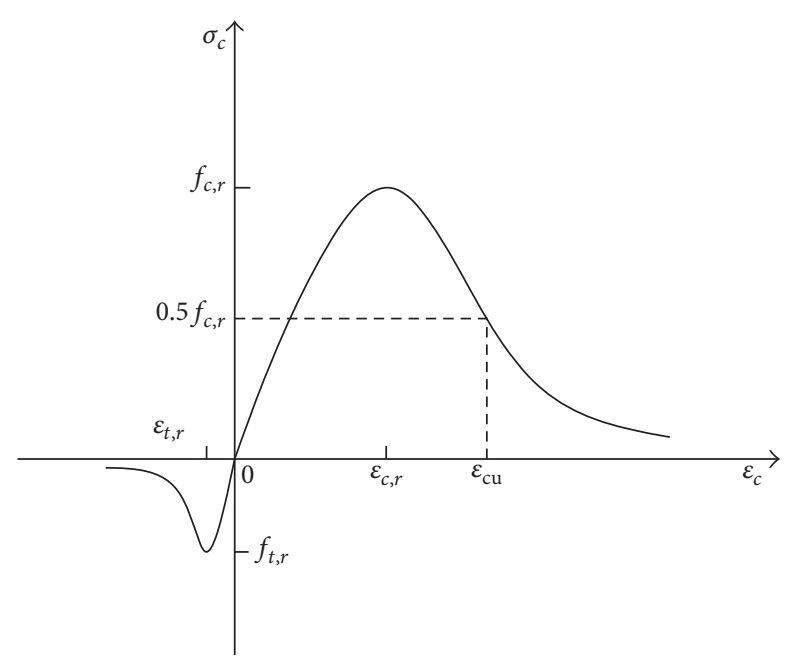

FIGURE 10: Stress-strain relationship of polypropylene fiber concrete.

As shown in Figure 11(a), the ideal elastic-plastic model is used for the relationship between stress and strain of rebars [3], where $f_{\text {sd }}$ is the yield strength of rebars, $\varepsilon_{y}$ is the corresponding strain, and $E_{s}$ is Young's modulus of rebars which is $2.0 \times 10^{5} \mathrm{MPa}$. As shown in Figure 11(b), a bilinear hardening plasticity relationship is used for the relationship between stress and strain of prestressed steel [3], where $f_{\mathrm{pk}}$ is the limit strength $1860 \mathrm{MPa}, \varepsilon_{\mathrm{pu}}$ is the corresponding strain taken as $0.02 ; f_{y}$ is yield strength, $f_{y}=0.92 \times f_{\mathrm{pk}}=$ 1711.2 $\mathrm{MPa}, \varepsilon_{y}$ is the corresponding strain, and $E_{p}$ is Young's modulus of prestressed steel which is $1.95 \times 10^{5} \mathrm{MPa}$. Poisson's ratio of rebars and prestressed steels is 0.3

3.2.3. Results of Mechanical Analysis for Crack Assessment. The vertical stress contours in both web sides before and after tensioning of the prestressed steels are obtained from the FE analysis. As shown in Figure 12, before the prestressed steels are tensioned, the maximum vertical tensile stress is just 1.1 MPa in the left web (Figure 12(a)) and 1.2 MPa in the right web (Figure 12(b)). The comparisons show that, after tensioning, the maximum vertical tensile stress is $3.5 \mathrm{MPa}$ in the left web (Figure 13(a)) and 3.6 MPa in the right web (Figure 13(b)), which occurs inside the webs, near the regions at both ends of the U-shaped girder. The stress exceeds the characteristic value of prismatic tensile strength of concrete $f_{\text {ct }}=3.3 \mathrm{MPa}$ [21], which will cause cracks at the end of the webs.

\section{Effects of the Design Parameters on Controlling Crack}

The U-shaped girder has an open thin-walled structural form to minimize self-weight, and the thickness of the web and bottom slabs is just $0.26 \mathrm{~m}$. Simultaneously, the prestressed steels are designed in the webs and bottom slab to bear the bending moment and shear force, as shown in Figure 4 . The biggest problem is that the U-shaped girder is too thin for the prestressing force. The structural dimension and prestressed steel design parameters have a considerable influence on the cause of cracks at the urban rail transit U-shaped girder during its construction phases. Thus, the effects of design parameters such as the flange slab thickness (Parameter 1), anchorage position of the prestressed steels (Parameter 2), and prestressed steel layout (Parameter 3) were investigated using FE analysis for controlling cracks.

4.1. Flange Slab Thickness (Parameter 1). To increase the entire longitudinal rigidity, in this analysis, the thickness of the flange slab was increased by $10 \mathrm{~cm}$. As shown in Figure 14, the thickness of the left flange slab was increased from $25 \mathrm{~cm}$ to $35 \mathrm{~cm}$, while the thickness of the right flange slab was increased from $25 \mathrm{~cm}$ to $35 \mathrm{~cm}$. Figure 15 showed the stress variation at both webs after tensioning with respect to Parameter 1 . It was found that the maximum vertical tensile stress was $2.5 \mathrm{MPa}$, approximately decreased by $70 \%$ of that in the original design. The analysis above verified that increasing the thickness of the web slabs was an effective method to control web slab cracks. However, increasing the thickness of the flange slab also increased the self-weight load, which accounted for a significant proportion of the design load and reduced the carrying capacity of the $\mathrm{U}$-shaped girder.

4.2. Anchorage Position (Parameter 2). From the analysis results of Figure 13, the cracks were near the inboard of the webs. Therefore, the prestressed steels anchorage positions at the webs were changed to discuss the effects on the 


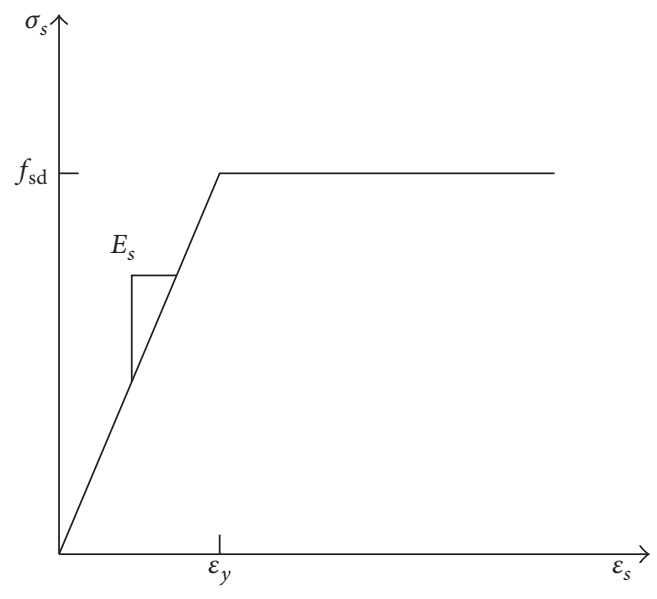

(a) Stress-strain relationship of rebars

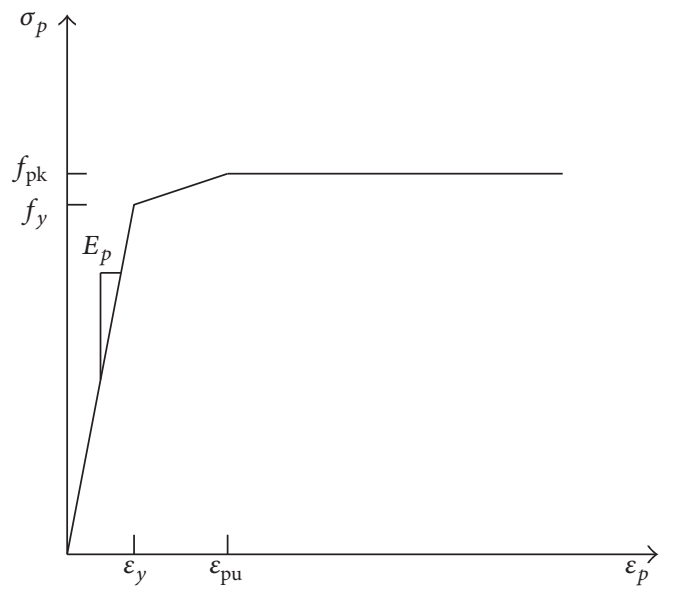

(b) Stress-strain relationship of prestressed steels

FIGURE 11: Stress-strain relationship of steels.

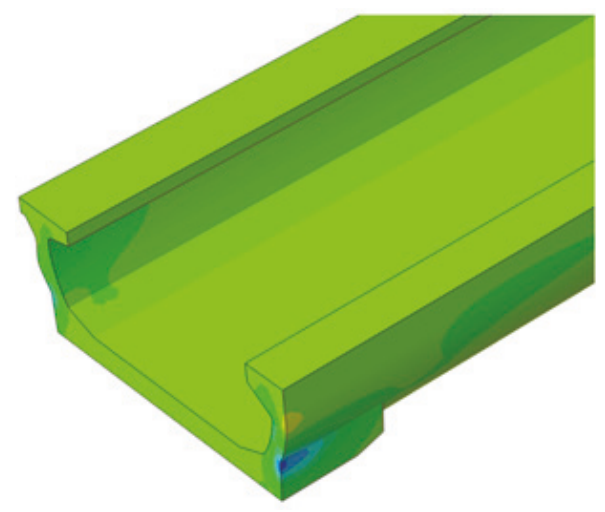

(a) Stress distribution of left web

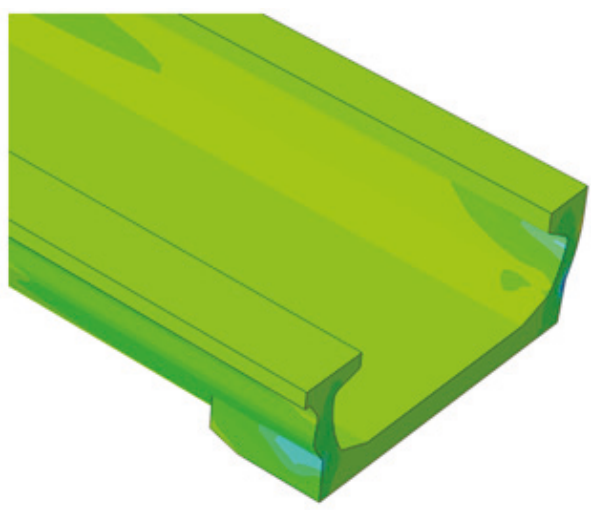

(b) Stress distribution of right web

FIGURE 12: Stress contours at the end of U-shaped girder before tensioning with original design.

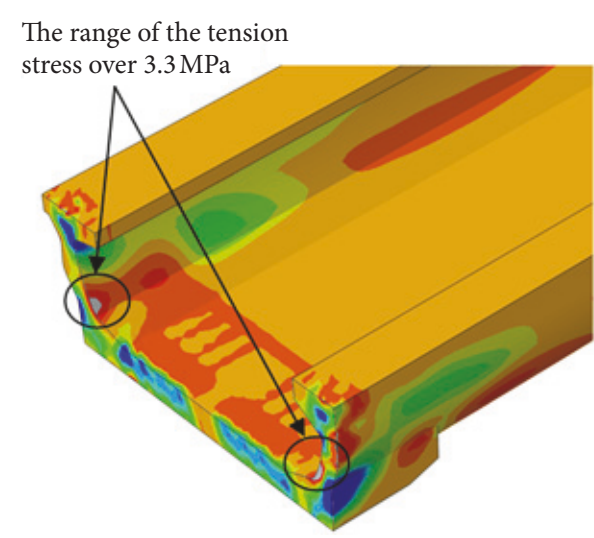

(a) Stress distribution in left web

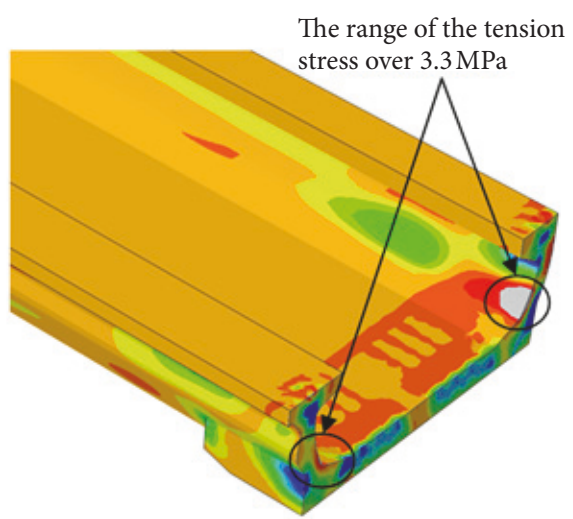

(b) Stress distribution in right web

FIGURE 13: Stress contours at the end of U-shaped girder after tensioning, with original design.

structure. In this analysis, the anchorage positions at the webs were horizontally moved $10 \mathrm{~cm}$ to the inboard, as shown in Figure 16. From the results shown in Figure 17, the maximum vertical tensile stress of the webs decreased from 3.6 MPa to 3.1 MPa compared to the original design. While the effects were less obvious than Parameter 1, the change in anchorage positions did not increase the self-weight of the Ushaped girder. Therefore, it was still an effective technique for controlling cracks.

4.3. Prestressed Steels Layout (Parameter 3). The conditions with different prestressed steel layouts are compared in 


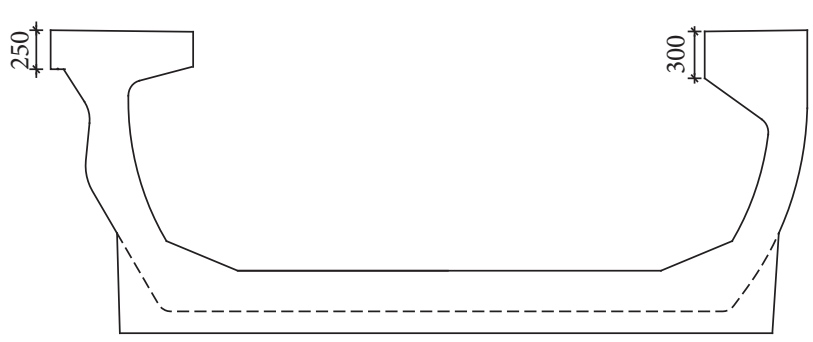

(a) Flange slab thickness in original design

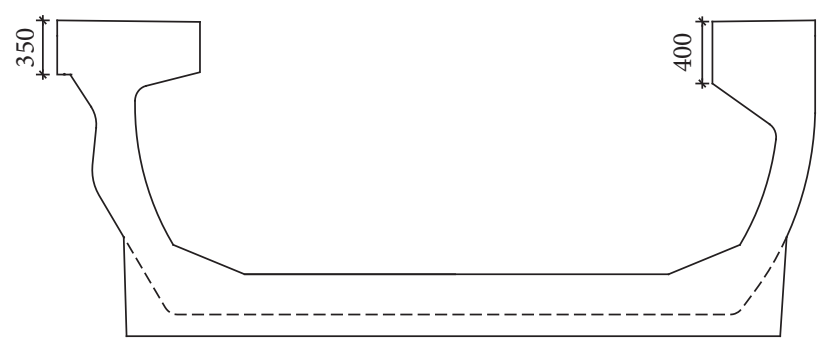

(b) Flange slab thickness with Parameter 1

FIGURE 14: Thickness of flange slab comparison (unit: $\mathrm{mm}$ ).

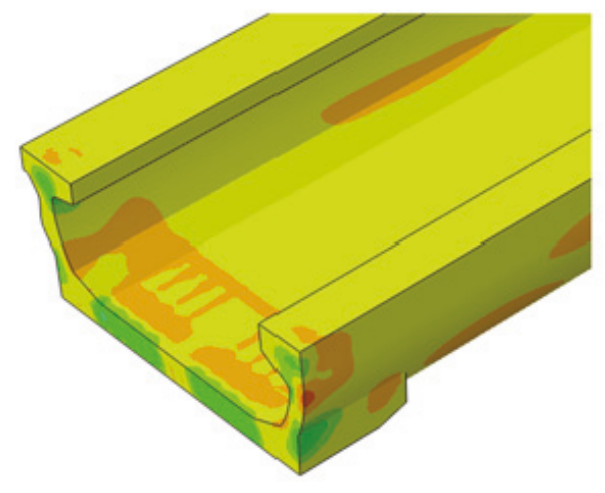

(a) Stress distribution of left web

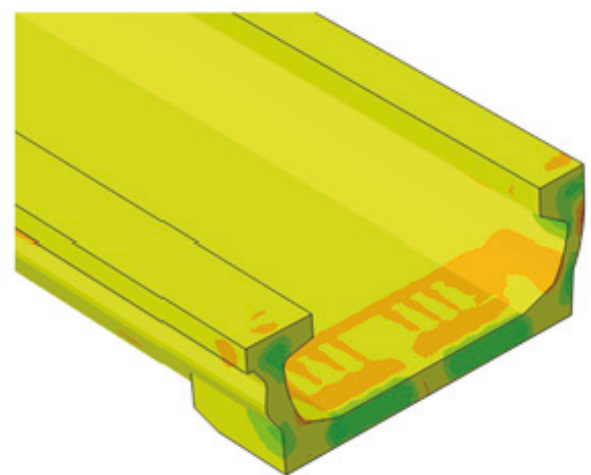

(b) Stress distribution of right web

FIGURE 15: Stress contours at the end of U-shaped girder after tensioning with Parameter 1.

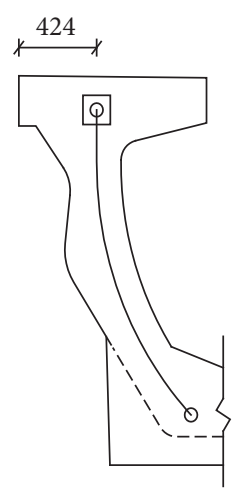

(a) Anchorage position in original design

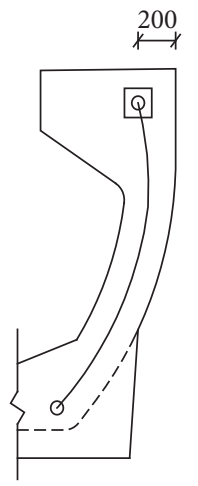

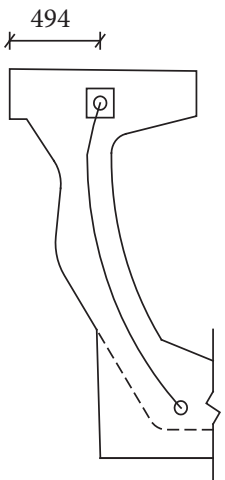

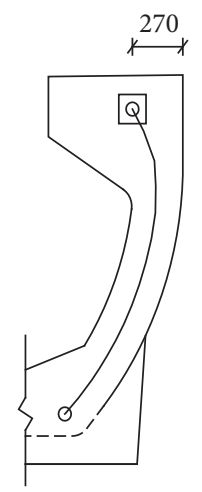

(b) Anchorage position of Parameter 2

FIGURE 16: Anchorage position of web prestressed steel comparison (unit: mm).

Table 2. The total number of prestressed steel units remained unchanged, but the prestressed steel layout was changed. The number of one-side web prestressed steel units $\mathrm{N} 1$ and $\mathrm{N1}^{\prime}$ was changed from 7 to 5 ; however, the number of bottom slab prestressed steel units $\mathrm{N} 4, \mathrm{~N} 4^{\prime}$ and $\mathrm{N} 5, \mathrm{~N} 5^{\prime}$ were increased from 10 to 11 . The comparisons showed that the maximum vertical tensile stress of the webs decreased from 3.6 MPa to $2.9 \mathrm{MPa}$ compared to the original design. The results verified that changing the prestressed steel layout was an effective means for web crack control. Although the ultimate flexural capacity of the U-shaped girder was similar to the original design, the shear capacity was weakened considerably, owing to the decrease in bent-up steel bars. However, changing the prestressed steel layout was needed to simultaneously satisfy the shear capacity requirements of the U-shaped girder.

\section{Conclusions}

This paper presents the outline of the cracks found in the webs of a U-shaped girder. The main cause of the cracks and the control methods for minimizing the occurrence of cracks are discussed based on the results of the FE analysis. The main conclusions can be summarized as follows. 


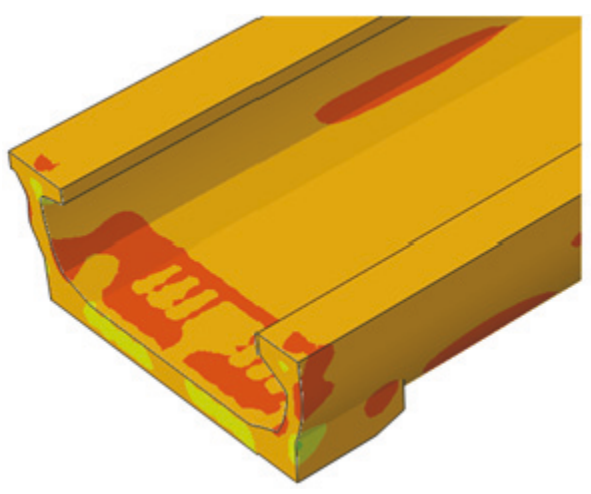

(a) Stress distribution of left web

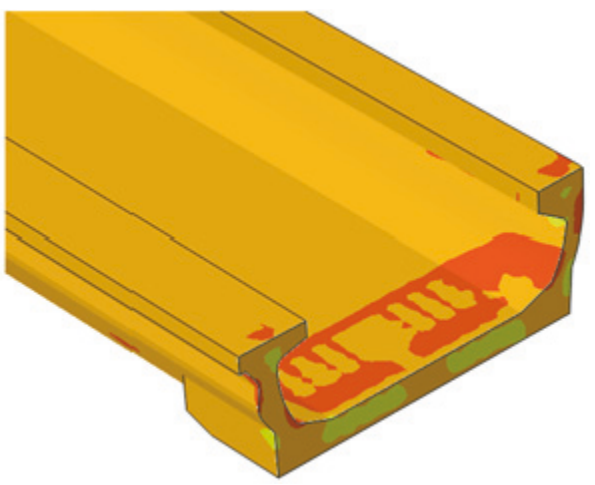

(b) Stress distribution of right web

FIGURE 17: Stress contours at the end of U-shaped girder after tensioning with Parameter 2.

TABLE 2: Number of prestressed steel units.

\begin{tabular}{|c|c|c|c|c|c|}
\hline & \multicolumn{2}{|c|}{ Web } & \multicolumn{3}{|c|}{ Bottom slab } \\
\hline & $\mathrm{N} 1, \mathrm{N1}^{\prime}$ & $\mathrm{N} 2, \mathrm{~N} 2^{\prime}$ & $\mathrm{N} 3, \mathrm{~N} 3^{\prime}$ & $\mathrm{N} 4, \mathrm{~N} 4^{\prime}$ & $\mathrm{N} 5, \mathrm{~N} 5^{\prime}$ \\
\hline Original design & 7 & 11 & 10 & 10 & 10 \\
\hline Parameter 3 & 5 & 11 & 10 & 11 & 11 \\
\hline
\end{tabular}

(1) It is considered that the U-shaped girder is an open thin-walled structure; thus, its rigidity, especially the web rigidity, is lower than in other traditional structures.

(2) Cracks occurred at both the end regions of the Ushaped girder webs after tensioning, one of the construction processes. The length of the crack was approximately $70 \mathrm{~cm}$, almost parallel to the centerline of the girder, and the width of the crack was approximately $0.4 \mathrm{~mm}$.

(3) The mechanical analysis results show that, after the tensioning process, the maximum vertical tensile stress exceeds the characteristic value of the prismatic tensile strength of concrete, which could cause cracks at the end of the webs.

(4) The web thickness and prestressed steel layout are the main factors that affect the tensile stresses in the web, but will also increase the self-weight and reduce the shear capacity of the U-shaped girder. The effect of the anchorage position is less obvious than the effect of the other parameters and will not reduce the shear and flexural properties.

(5) These parameters should be comprehensively considered in the design to prevent cracks during construction and meet the requirement of the carrying capacity and economical efficiency.

\section{Conflicts of Interest}

The authors declare that they have no conflicts of interest.

\section{Acknowledgments}

The authors would like to acknowledge the financial support received from the National Natural Science Foundation of China (Grant no. 51379113) and the support received from the
National Key Research and Development Program (Grant no. 2016YFC0600803).

\section{References}

[1] B. Wang, Q. Pu, and G. Bai, "Environmental vibration measurement and analysis of U-girder coupling vibration of new vehicle-bridge," Dizhen Gongcheng yu Gongcheng Zhendong (Earthquake Engineering and Engineering Vibration), vol. 32, no. 1, pp. 78-85, 2012.

[2] Wu W., "Mechanical analysis and optimum design of continuous girder with u-shaped cross section used in urban rail transit," Railway Engineering, vol. 5, pp. 20-22, 2017.

[3] X. Ruan, X. Shi, and X. Li, "Failure analysis of tendon breakout on bottom slab of a pre-stressed concrete box gird bridge during construction," Engineering Failure Analysis, vol. 25, pp. 291-303, 2012.

[4] D.-Y. Moon, J. Sim, and H. Oh, "Practical crack control during the construction of precast segmental box girder bridges," Computers \& Structures, vol. 83, no. 31, pp. 2584-2593, 2005.

[5] A. Dall'asta, L. Ragni, and A. Zona, "Simplified method for failure analysis of concrete beams prestressed with external tendons," Journal of Structural Engineering, vol. 133, no. 1, pp. 121-131, 2007.

[6] Q. Wang, S. Nakamura, T. Okumatsu, and T. Nishikawa, "Comprehensive investigation on the cause of a critical crack found in a diagonal member of a steel truss bridge," Engineering Structures, vol. 132, pp. 659-670, 2017.

[7] T. Krakhmal'ny, S. Evtushenko, and M. Krakhmal'naya, "New system of monitoring of a condition of cracks of small reinforced concrete bridge constructions," Procedia Engineering, vol. 150, pp. 2369-2374, 2016.

[8] K.-K. Yun and P. Choi, "Causes and controls of cracking at bridge deck overlay with very-early strength latex-modified concrete," Construction and Building Materials, vol. 56, pp. 5362, 2014. 
[9] X. Zhao, X.-J. He, S. Yan, and N. P. Anh, "Computational and simulation analysis of pull-out fiber reinforced concrete," Advances in Materials Science and Engineering, vol. 2014, Article ID 576052, 7 pages, 2014.

[10] L. Wu, J. Nie, J. Lu, J. Fan, and C. S. Cai, "A new type of steel-concrete composite channel girder and its preliminary experimental study," Journal of Constructional Steel Research, vol. 85, pp. 163-177, 2013.

[11] R. Mott and M. A. Diaz, "Distribution factors for short-haul vehicular loads on prestressed concrete open box beam (UBeam) bridges," Practice Periodical on Structural Design and Construction, vol. 15, no. 2, pp. 101-108, 2010.

[12] L. Huang, L. Zhang, and B. Chen, "Contrastive analysis of structural design of precast $\mathrm{T}$ beam bridge and composite $\mathrm{U}$ beam bridge," World Bridges, vol. 41, no. 2, pp. 21-26, 2013.

[13] ABAQUS Standard User's Manual, The Abaqus Software is a product of Dassault Systemes Simulia Corp., Providence, RI, USA Dassault Systemes, USA, 6.8 edition, 2008.

[14] T. Simões, H. Costa, D. Dias-da-Costa, and E. Júlio, "Influence of fibres on the mechanical behaviour of fibre reinforced concrete matrixes," Construction and Building Materials, vol. 137, pp. 548-556, 2017.

[15] A. Caggiano, S. Gambarelli, E. Martinelli, N. Nisticò, and M. Pepe, "Experimental characterization of the post-cracking response in Hybrid Steel/Polypropylene Fiber-Reinforced Concrete," Construction and Building Materials, vol. 125, pp. 10351043, 2016.

[16] V. Afroughsabet and T. Ozbakkaloglu, "Mechanical and durability properties of high-strength concrete containing steel and polypropylene fibers," Construction and Building Materials, vol. 94, pp. 73-82, 2015.

[17] G. M. Sadiqul Islam and S. D. Gupta, "Evaluating plastic shrinkage and permeability of polypropylene fiber reinforced concrete," International Journal of Sustainable Built Environment, vol. 5, no. 2, pp. 345-354, 2016.

[18] N. Liang, The mechanics performance test of multi-scale polypropylene fiber concrete and the study of tension and compression damage constitutive model. Chongqing University.

[19] N. Liang, J. Dai, and X. Liu, "Study on tensile damage constitutive model for multiscale polypropylene fiber concrete," Advances in Materials Science and Engineering, vol. 2016, Article ID 9168984, 2016.

[20] Ministry of Housing and Urban-Rural Development of the People's Republic of China. Code for design of concrete structures (GB50010-2010), 2005.

[21] Ministry of Communications of the People's Republic of China. Code for design on reinforced and prestressed concrete structure of railway bridge and culvert (TB 10002.3-2005), 2005. 

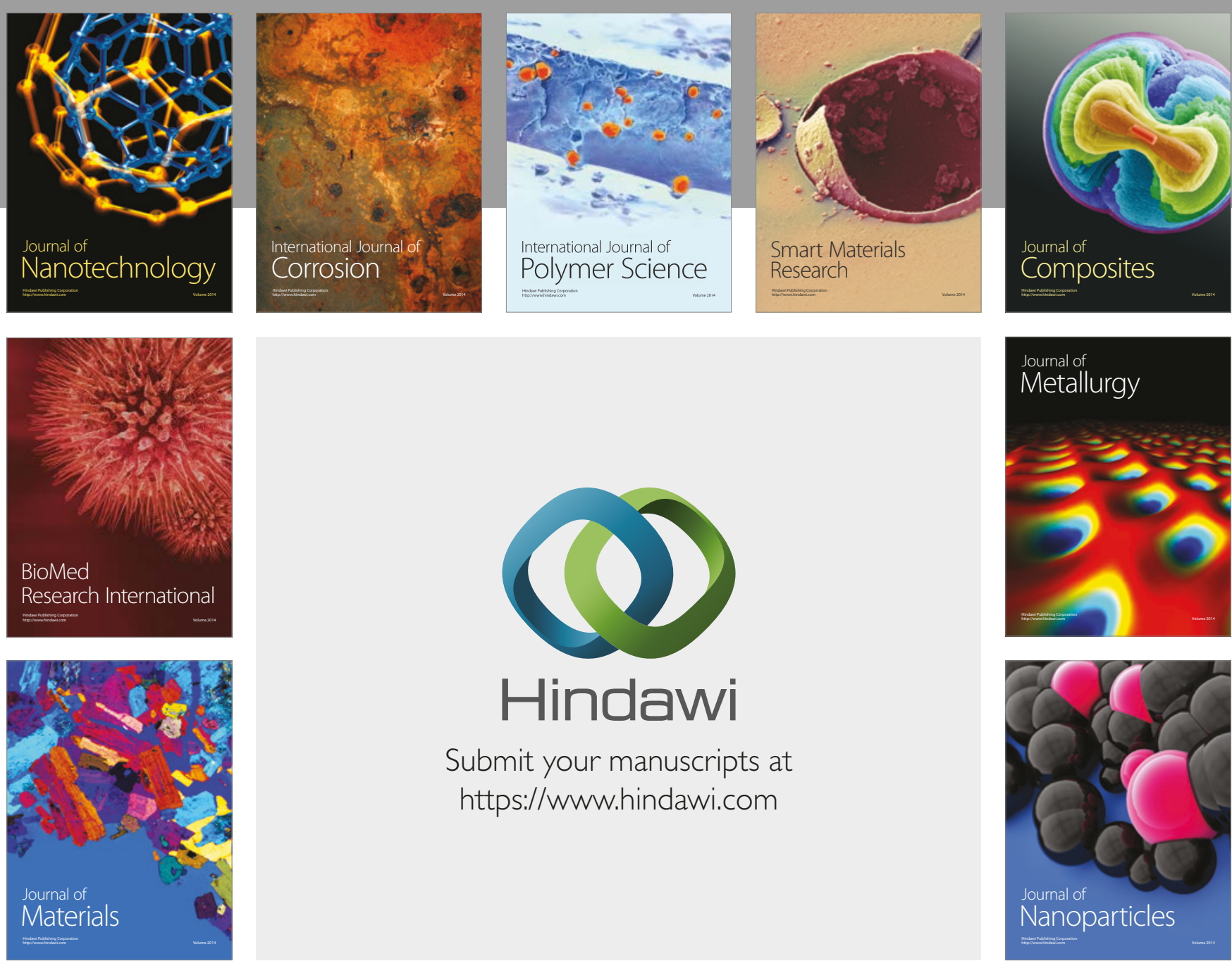

\section{Hindawi}

Submit your manuscripts at

https://www.hindawi.com
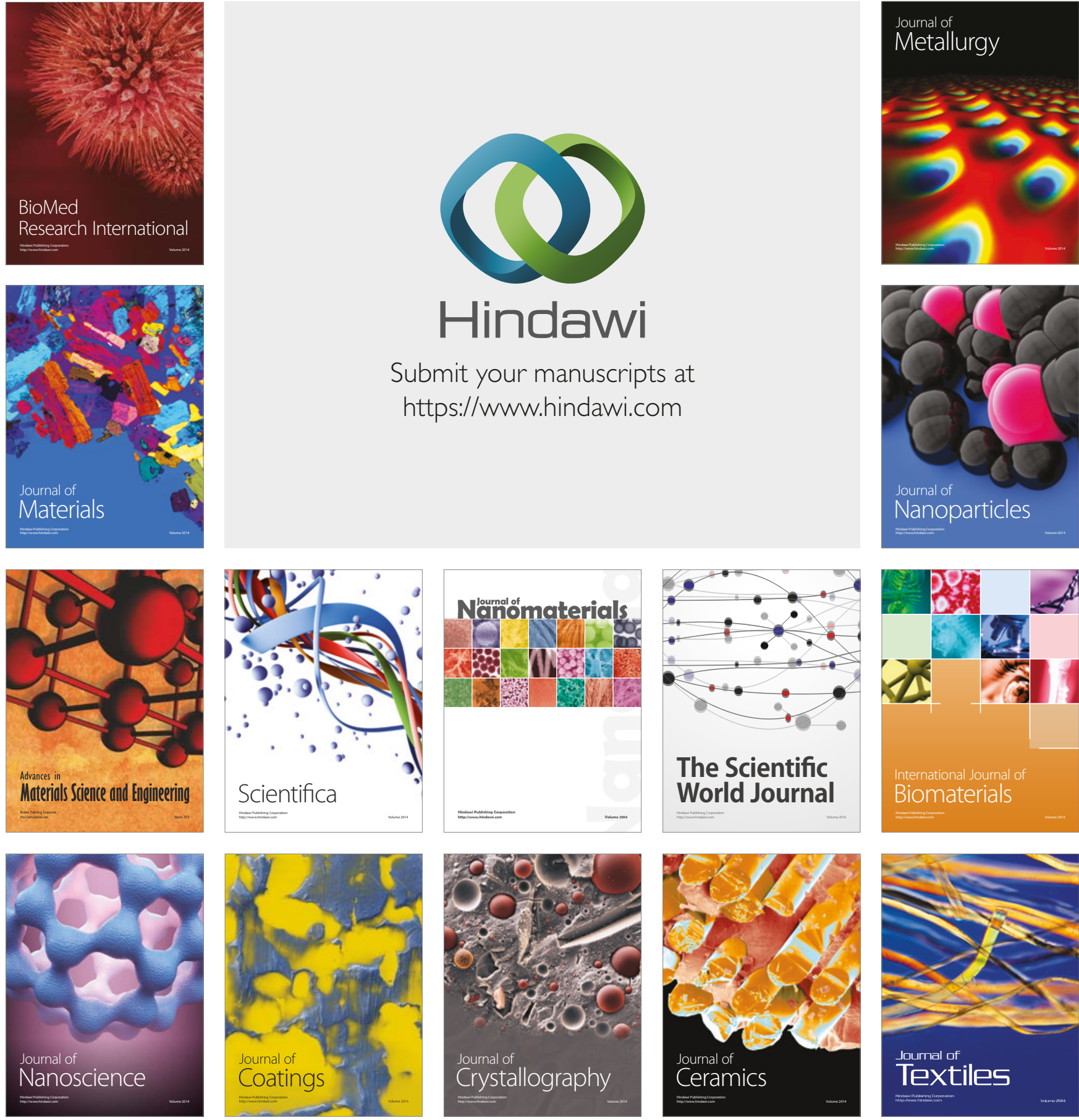

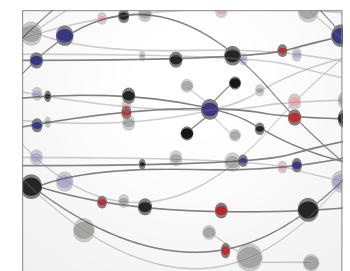

The Scientific World Journal
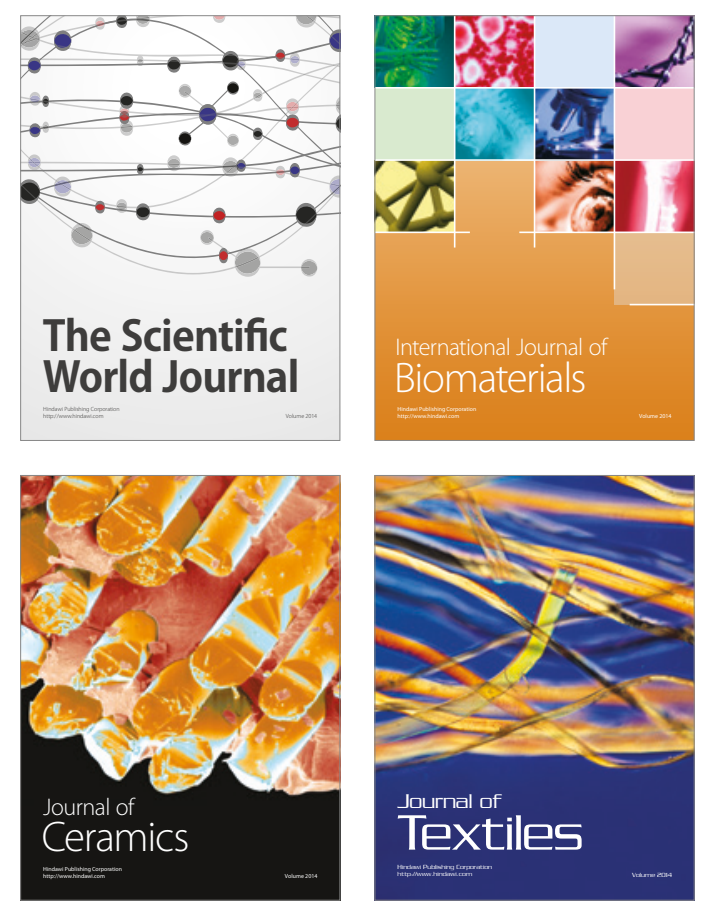